\title{
Multilocus sequence typing of azole-resistant Candida auris strains, South Africa
}

\begin{tabular}{|c|c|}
\hline $\begin{array}{l}\text { Authors: } \\
\text { Rindidzani M } \\
\text { Mabatho Mh } \\
\text { Craig Corcora } \\
\text { Nelesh P. Gov }\end{array}$ & $\begin{array}{l}\text { gobo }^{1,2} \text { (I) } \\
\text { anga }^{1} \text { (D) } \\
\text { ender }^{2} \text { (I) }\end{array}$ \\
\hline $\begin{array}{l}\text { Affiliations: } \\
{ }^{1} \text { Centre for H } \\
\text { associated In } \\
\text { Antimicrobial } \\
\text { Mycoses, Div } \\
\text { National Heal } \\
\text { Service, Natic } \\
\text { Communicab } \\
\text { Johannesburg }\end{array}$ & $\begin{array}{l}\text { althcare- } \\
\text { ections, } \\
\text { Resistance and } \\
\text { sion of the } \\
\text { h Laboratory } \\
\text { nal Institute for } \\
\text { Diseases, } \\
\text { South Africa }\end{array}$ \\
\hline $\begin{array}{l}{ }^{2} \text { Ampath Nati } \\
\text { Laboratory, } \mathrm{Pr} \\
\text { South Africa }\end{array}$ & $\begin{array}{l}\text { nal Reference } \\
\text { etoria, }\end{array}$ \\
\hline $\begin{array}{l}\text { Research Proj } \\
\text { Project Numb }\end{array}$ & $\begin{array}{l}\text { ect Registration: } \\
\text { er: R14/49 }\end{array}$ \\
\hline $\begin{array}{l}\text { Correspondin } \\
\text { Rindidzani Ma } \\
\text { rmagobo@ya }\end{array}$ & $\begin{array}{l}\text { g author: } \\
\text { gobo, } \\
\text { hoo.com }\end{array}$ \\
\hline $\begin{array}{l}\text { Dates: } \\
\text { Received: } 28 \\
\text { Accepted: } 16 \\
\text { Published: } 23\end{array}$ & $\begin{array}{l}\text { May } 2019 \\
\text { lan. } 2020 \\
\text { Mar. } 2020\end{array}$ \\
\hline $\begin{array}{l}\text { How to cite tl } \\
\text { Magobo R, M } \\
\text { Corcoran C, G } \\
\text { Multilocus se } \\
\text { of azole-resist } \\
\text { auris strains, } \\
\text { Afr J Infect Di } \\
\text { a116. https:// } \\
\text { org/10.4102/ }\end{array}$ & $\begin{array}{l}\text { is article: } \\
\text { langa M, } \\
\text { ovender NP. } \\
\text { quence typing } \\
\text { ant Candida } \\
\text { outh Africa. S } \\
\text { 2020;35(1), } \\
\text { doi. } \\
\text { ajid.v35i1.116 }\end{array}$ \\
\hline $\begin{array}{l}\text { Copyright: } \\
\text { (C) 2020. The } \\
\text { Licensee: AOS } \\
\text { is licensed un } \\
\text { Creative Com } \\
\text { Attribution Lic }\end{array}$ & $\begin{array}{l}\text { uthors. } \\
\text { IS. This work } \\
\text { ler the } \\
\text { nons } \\
\text { ense. }\end{array}$ \\
\hline Read online: & \\
\hline 물물 & $\begin{array}{l}\text { Scan this QR } \\
\text { code with your } \\
\text { smart phone or } \\
\text { mobile device } \\
\text { to read online. }\end{array}$ \\
\hline
\end{tabular}

Background: Candida auris is an emerging multidrug-resistant fungal pathogen associated with high mortality.

Methods: We investigated the genetic relatedness of clinical C. auris isolates from patients admitted to either public- or private-sector hospitals, which were submitted to a reference laboratory from 2012 to 2015. Patient demographics and clinical details were recorded. We performed antifungal susceptibility testing, sequencing of the hotspot 1 and 2 regions of the FKS1 and FKS2 genes for all isolates with an echinocandin minimum inhibitory concentration (MIC) of $\geq 1 \mu \mathrm{g} / \mathrm{mL}$ and cluster analysis using multilocus sequence typing.

Results: Eighty-five isolates were confirmed as $C$. auris. The median patient age was 59 years [inter-quartile range (IQR): $48-68$ years], with male patients accounting for $68 \%$ of cases. Specimen types included urine (29\%), blood (27\%), central venous catheter tips $(25 \%)$, irrigation fluid $(7 \%)$, tissue $(5 \%)$, respiratory tract specimens $(4 \%)$ and other $(3 \%)$. Ninety-seven per cent of isolates were resistant to fluconazole, $7 \%$ were resistant to both fluconazole and voriconazole, $8 \%$ were resistant to both fluconazole and echinocandins (considered multidrug resistant) and all were susceptible to amphotericin B. Of the 15 randomly selected fluconazole-resistant isolates, 14 isolates had an isavuconazole MIC $\leq 1$ $\mu \mathrm{g} / \mathrm{mL}$. No FKS mutations were detected. Multilocus sequence typing (MLST) analysis grouped isolates into two clusters: cluster 1 and cluster 2 comprising 83 and 2 isolates, respectively.

Conclusions: Azole-resistant C. auris strains circulating in South African hospitals were related by MLST, but the possibility of nosocomial transmission should be explored using a more discriminatory technique, for example, whole genome sequencing.

Keywords: Candida auris; azole resistant; multilocus sequence typing; FKS sequencing; South Africa.

\section{Introduction}

Since its first description in Japan in 2009, cases of Candida auris with varying clinical manifestations have been reported from Asia, Africa, South America, Europe, North America and Australasia. ${ }^{1,2,3,4,5,6,7,8}$ However, the global prevalence and the geographic extent of $C$. auris disease are likely underestimated, especially in the low- and middle-income countries, because conventional laboratory methods misidentify the fungus and relatively few resource-limited countries have the capacity for identification by mass spectrometric or molecular methods. ${ }^{4,5,6,7}$

Of concern, C. auris is almost universally resistant to fluconazole, and some isolates have reduced susceptibility to voriconazole, amphotericin B and the echinocandins. ${ }^{4,6,9}$ As expected, persistent or breakthrough fungaemia has been reported among patients initially receiving fluconazole therapy, resulting in death in some cases. ${ }^{2,4}$ Candida auris has been associated with large healthcare-associated outbreaks owing to its ability to transmit from person to person, persist for long periods in the hospital environment and resist chemical disinfection by certain products. . $111,12,13,14^{2}$

A whole genome sequencing (WGS) study showed that C. auris strains from each of three continents namely, South Asia, South America and Africa, were almost clonal, with simultaneous independent emergence of clonal groups in each continent being hypothesised. ${ }^{10}$ Multilocus sequence typing (MLST) and amplified fragment length polymorphism (AFLP) typing have also demonstrated strain clustering by geographical region. ${ }^{11,14}$ More recently, it has become clear that patients and strains have crossed borders, seeding outbreaks in new locations. ${ }^{15,16}$ 
In light of an emerging epidemic of $C$. auris infections among hospitalised patients in parts of South Africa, we sought to describe the antifungal susceptibility profile and genetic relatedness of a convenience sample of $C$. auris strains referred to a South African reference laboratory.

\section{Materials and methods Laboratory surveillance}

A case was defined as a patient of any age admitted to any South African hospital with first isolation of $C$. auris from any specimen (representing either infection or colonisation) from January 2012 to December 2015. Referring laboratories submitted suspected or confirmed isolates of $C$. auris to the National Institute for Communicable Diseases (NICD) in Johannesburg. Only cases with viable isolates referred to NICD were included in this study. These cases are thus not necessarily representative of all diagnosed cases of $C$. auris over this time period. Corresponding laboratory reports, containing patient demographic information such as age, sex, hospital, specimen type and date of specimen collection were also submitted.

\section{Species-level identification and antifungal susceptibility testing}

Laboratory identification systems regularly misidentify C. auris in a predictable way. Referring laboratories, therefore, submitted isolates to the National Mycology Reference Laboratory at NICD when C. auris was suspected for species-level confirmation and antifungal susceptibility testing. These were most often yeasts with high fluconazole minimum inhibitory concentrations (MICs) which had been identified as Candida haemulonii by Vitek 2 YST using software version 7.0 or earlier versions (bioMérieux, Marcy l'Etoile, France), as Rhodotorula glutinis by API 20C Aux or API ID 32C (bioMérieux), as Saccharomyces cerevisiae by Auxacolor (BioRad, Hercules, CA, USA) or as Candida famata by MicroScan WalkAway (Beckman Coulter, Brea, CA, USA). ${ }^{17}$ Isolates were submitted on sabouraud agar plates or in sealed bottles containing Dorset transport medium [Diagnostic Media Products (DMP), Johannesburg, South Africa] to NICD. We initially performed phenotypic identification using CHROMagar Candida medium (Mast Diagnostics, Merseyside, UK). We subjected all isolates to matrix-assisted laser desorption ionization-time of flight (MALDI-TOF) (Bruker, Bremen, Germany) mass spectrometric analysis using Biotyper v3.1 software (Bruker Ltd., Coventry, UK). Identification of C. auris isolates was then confirmed by polymerase chain reaction (PCR) amplification and sequencing of the internal transcribed spacer (ITS) domain of the ribosomal ribonucleic acid (RNA) gene and the D1-D2 region of the 28S subunit using universal primers. ${ }^{18}$ Antifungal susceptibility testing for fluconazole, voriconazole, itraconazole, posaconazole, caspofungin, anidulafungin, micafungin and flucytosine was performed using commercially available microbroth dilution panels containing Alamar blue (Thermo Fisher Scientific, Cleveland, OH, USA). Neither the European
Committee on Antifungal Susceptibility Testing (EUCAST) nor the U.S.-based Clinical and Laboratory Standards Institute (CLSI) has defined clinical breakpoints for C. auris. For epidemiological purposes, resistance was conservatively defined as follows (adapted from Lockhart et al. ${ }^{10}$ ): fluconazole $\geq 32 \mu \mathrm{g} / \mathrm{mL}$, voriconazole $\geq 2 \mu \mathrm{g} / \mathrm{mL}$ (similar to CLSI breakpoints for Candida krusei), flucytosine $\geq 128 \mu \mathrm{g}$ / $\mathrm{mL}$ and amphotericin $\mathrm{B} \geq 2 \mu \mathrm{g} / \mathrm{mL}$. Echinocandin resistance was defined using the following tentative MIC breakpoints (adapted from the Centers for Disease Control and Prevention $[C D C]^{19}$ ): anidulafungin and micafungin $\geq 4 \mu \mathrm{g} /$ $\mathrm{mL}$. Caspofungin is an unreliable indicator of echinocandin resistance, and caspofungin MICs were not interpreted..$^{20}$ Isavuconazole susceptibility testing was performed on a random sample of 15 fluconazole-resistant isolates using the Etest method. Candida parapsilosis ATCC 22019 and C. krusei ATCC 6258 strains were included in quality control (QC) runs on all days of testing, and MICs were found to be within the expected QC ranges.

\section{FKS gene sequencing of $C$. auris isolates}

We sequenced the hotspot 1 and 2 regions of the FKS1 and FKS2 genes for all isolates with an echinocandin MIC of $\geq 1$ $\mu \mathrm{g} / \mathrm{mL}^{21,22}$ All sequences were aligned with the FKS sequences of a hypothetical protein obtained from the draft genome sequence of $C$. auris strain VPCI 479/P/13 (accession number CVRJ00000000) from India ${ }^{23}$ and a wild-type Candida albicans strain ATCC 90028 (GQ456066).

\section{Genotyping of $\boldsymbol{C}$. auris isolates}

To determine the genetic relatedness among the $C$. auris strains, we sequenced four loci (ITS, D1-D2, RPB1 and RPB2) using a previously published method. ${ }^{14}$ GenBank accession numbers for the sequence data of ITS, D1-D2, RPB1 and RPB2 loci are attached in the supplementary table. Briefly, we extracted deoxyribonucleic acid (DNA) from single colonies using Zymo ZR fungal/Bacterial DNA MiniPrep (Zymo Research Corporation, Irvine, CA, USA). PCR amplification was performed using primers adopted from Prakath et al. ${ }^{14}$; the following control strains were included: MRL208 (KJ126758) and MRL209 (KJ126759). PCR amplicons were purified using Exonuclease I/Shrimp alkaline phosphatase enzymes (Thermo Fisher Scientific). Deoxyribonucleic acid sequencing was performed with the same primers used for PCR using BigDye terminator version 3.1 in an ABI 3500 genetic analyser (Applied Biosystems, Foster City, CA, USA). Identification of C. auris was performed by pairwise sequence comparison of the ITS region using the NCBI BLAST algorithm (www. ncbinlm.nih.gov/blast). We performed multiple-sequence alignment of concatenated sequences using ClustalW. ${ }^{24}$ Using the final MLST data set, we generated a phylogenetic tree by a neighbour-joining statistical method using 2000 bootstrap replications on MEGA $6^{25}$ (Figure 1). A cluster was defined as isolates from different patients which shared a common ancestor, with a bootstrap value between $90 \%$ and $100 \%$. 


\section{Ethical considerations}

Ethical clearance to conduct the study was obtained from the Human Research Ethics Committee of the University of the Witwatersrand (Project Research Number: R14/49, Ethical Clearance Number: M140159) on 31 January 2014.

\section{Results}

From January 2012 to December 2015, 86 viable isolates from 77 patients were referred to NICD for identification and antifungal susceptibility testing. One case of C. haemulonii infection ( 1 isolate) was excluded. Cases of $C$. auris infection or colonisation were diagnosed at 32 hospitals, 27 of which were located in Gauteng Province, and most of these were in the City of Johannesburg or Tshwane. The remaining cases were diagnosed at hospitals located in seven other provinces, which included North West, Limpopo, KwaZulu-Natal, Free State, Eastern Cape, Western Cape and Mpumalanga. Seventy-two (85\%) isolates were from patients admitted to private-sector hospitals; the remainder were from publicsector hospitals. The median age of cases was 59 years [inter-quartile range (IQR), 48-68 years]. Male patients accounted for $68 \%(50 / 74)$ of the cases. Twenty-nine per cent $(22 / 75)$ of isolates were cultured from urine followed by $27 \%$ $(20 / 75)$ from blood, $25 \%$ (19/75) from central venous catheter tips, 7\% (5/75) from irrigation fluid, 5\% (4/75) from tissue, $4 \%(3 / 75)$ from respiratory tract specimens and the remainder from miscellaneous sites. Twenty-four (32\%) of 76 patients had hospital ward information available. Of these, 12 (57\%) were admitted to an intensive care unit, $6(25 \%)$ to a trauma unit, $3(13 \%)$ to a burns unit, $2(8 \%)$ to general wards and $1(4 \%)$ to a neurosurgery ward. No further clinical or outcome information was available.

\section{Antifungal susceptibility testing}

Antifungal susceptibility testing was performed on all 85 C. auris isolates (Table 1). Of these, 82 (97\%) were resistant to fluconazole with an $\mathrm{MIC}_{50}$ and $\mathrm{MIC}_{90}$ of $128 \mu \mathrm{g} / \mathrm{mL}$ and $256 \mu \mathrm{g} / \mathrm{mL}$, respectively. Six (7\%) isolates were resistant to voriconazole and seven (8\%) isolates were resistant to echinocandins. All six voriconazole-resistant isolates were resistant to fluconazole although none of these were resistant to echinocandins. All seven echinocandin-resistant isolates $(8 \%)$ were resistant to fluconazole and were thus considered multidrug-resistant, that is, resistant to $\geq 2$ classes of antifungal agents. No isolates were resistant to flucytosine or amphotericin B. Posaconazole and itraconazole had potent in vitro activity with an $\mathrm{MIC}_{50}$ and $\mathrm{MIC}_{90}$ of $0.25 \mu \mathrm{g} / \mathrm{mL}$ and $0.12 \mu \mathrm{g} / \mathrm{mL}$, respectively (Table 1 ). The $\mathrm{MIC}_{50}$ (range) for isavuconazole was $0.19 \mu \mathrm{g} / \mathrm{mL}(0.06 \mu \mathrm{g} / \mathrm{mL}-4 \mu \mathrm{g} / \mathrm{mL})$ for 15 fluconazole-resistant strains.

\section{FKS sequencing}

We sequenced the hot spot regions of $F K S 1$ and $F K S 2$ genes of 14 isolates with an echinocandin MIC $\geq 1 \mu \mathrm{g} / \mathrm{mL}$. One isolate was resistant to both anidulafungin and micafungin, and six isolates were resistant to micafungin. No resistanceassociated mutations were detected within the hot spot regions of $F K S 1$ and $F K S 2$ genes.

\section{Genotyping of $\boldsymbol{C}$. auris isolates}

Eighty-five isolates from 76 patients were confirmed as C. auris using ITS sequencing. Multilocus sequence typing was performed on all 85 isolates. Phylogenetic analysis grouped the isolates into two clusters, cluster 1 comprising 83 isolates and cluster 2 comprising two isolates (Figure 1). The two isolates belonging to cluster 2 had single-nucleotide polymorphisms (SNPs) within the RPB1 locus, when compared to cluster 1 isolates, and had been cultured from patients at two separate hospitals. Five patients had more than one isolate; isolates cultured from each of these individual patients had similar MLST profiles. A phylogenetic tree based on ITS sequences showed that South African isolates were closely related to Indian and Kuwaiti isolates (Figure 2).

\section{Discussion}

Candida auris is an emerging antifungal-resistant pathogen causing outbreaks globally. In South Africa, C. auris has reportedly caused large outbreaks in several hospitals, predominantly in private-sector hospitals in Gauteng Province. ${ }^{26}$ Almost all isolates in our case series were resistantw to fluconazole, and a smaller proportion were resistant to both fluconazole and voriconazole or both azole

TABLE 1: Antifungal susceptibility profile of Candida auris isolates $(n=85)$.

\begin{tabular}{|c|c|c|c|c|c|c|c|c|c|c|c|c|c|c|c|c|c|c|c|c|c|c|}
\hline \multirow[t]{2}{*}{ Antifungal agent } & \multicolumn{16}{|c|}{ Number of isolates with MIC $(\mu \mathrm{g} / \mathrm{mL})$ of } & \multicolumn{2}{|c|}{ Susceptible } & \multicolumn{2}{|c|}{ Resistant $\uparrow$} & \multirow{2}{*}{$\begin{array}{c}\text { MIC }_{50} \\
(\mu \mathrm{g} / \mathrm{mL})\end{array}$} & \multirow{2}{*}{$\begin{array}{c}\mathrm{MIC}_{90} \\
(\mu \mathrm{g} / \mathrm{mL})\end{array}$} \\
\hline & $<0.008$ & 0.015 & 0.03 & 0.06 & 0.12 & 0.25 & 0.5 & 1 & 2 & 4 & 8 & 16 & 32 & 64 & 128 & 256 & $N$ & $\%$ & $N$ & $\%$ & & \\
\hline Amphotericin B & - & - & - & - & - & 2 & 42 & 41 & - & - & - & - & - & - & - & - & 85 & 100 & 0 & 0 & 0.5 & 1 \\
\hline Fluconazole & - & - & - & - & - & - & - & - & - & - & & 3 & $5 \S$ & $23 \S$ & $27 \S$ & $27 \S$ & 3 & 3 & 82 & 97 & 128 & 256 \\
\hline Voriconazole & 2 & 6 & 3 & 16 & 24 & 11 & 11 & 6 & $2 \S$ & $3 \S$ & $1 \S$ & - & - & - & - & - & 79 & 93 & 6 & 7 & 0.12 & 1 \\
\hline Posaconazole & 38 & 22 & 13 & 6 & 2 & 2 & 1 & 1 & - & - & - & - & - & - & - & - & - & & - & & 0.015 & 0.06 \\
\hline Itraconazole & - & 11 & 40 & 23 & 6 & 5 & - & - & - & - & - & - & - & - & - & - & - & & - & & 0.03 & 0.12 \\
\hline Isavuconazole & - & - & - & 1 & 5 & 5 & 2 & 1 & & 1 & - & - & - & - & - & - & - & & - & & 0.19 & 0.38 \\
\hline Flucytosine & - & 1 & 1 & 67 & 11 & - & - & - & - & - & - & - & - & 5 & & & 85 & 100 & 0 & 0 & 0.06 & 0.12 \\
\hline Caspofungin & 8 & - & 26 & 26 & 6 & 6 & & 3 & 3 & 6 & 1 & - & - & - & - & - & - & & - & & 0.06 & 2 \\
\hline Anidulafungin & - & - & 43 & 18 & 4 & 7 & 2 & 8 & 2 & $1 \S$ & - & - & - & - & - & - & 84 & 99 & 1 & 1 & 0.03 & 1 \\
\hline Micafungin & - & 11 & 31 & 21 & 8 & 2 & & 1 & 4 & $5 \S$ & $2 \S$ & - & - & - & - & - & 78 & 92 & 7 & 8 & 0.06 & 2 \\
\hline
\end{tabular}

MIC, minimum inhibitory concentration.

$\dagger$, In the absence of breakpoints, resistance was arbitrarily defined as follows: fluconazole $\geq 32 \mu \mathrm{g} / \mathrm{mL}$, voriconazole $\geq 2 \mu \mathrm{g} / \mathrm{mL}$, anidulafungin/ micafungin $\geq 4 \mu \mathrm{g} / \mathrm{mL}$, flucytosine $\geq 128 \mu \mathrm{g} / \mathrm{mL}$ and amphotericin $\mathrm{B} \geq 2 \mu \mathrm{g} / \mathrm{mL} ; \$, n=15 ; \S$, number of isolates that were resistant. 


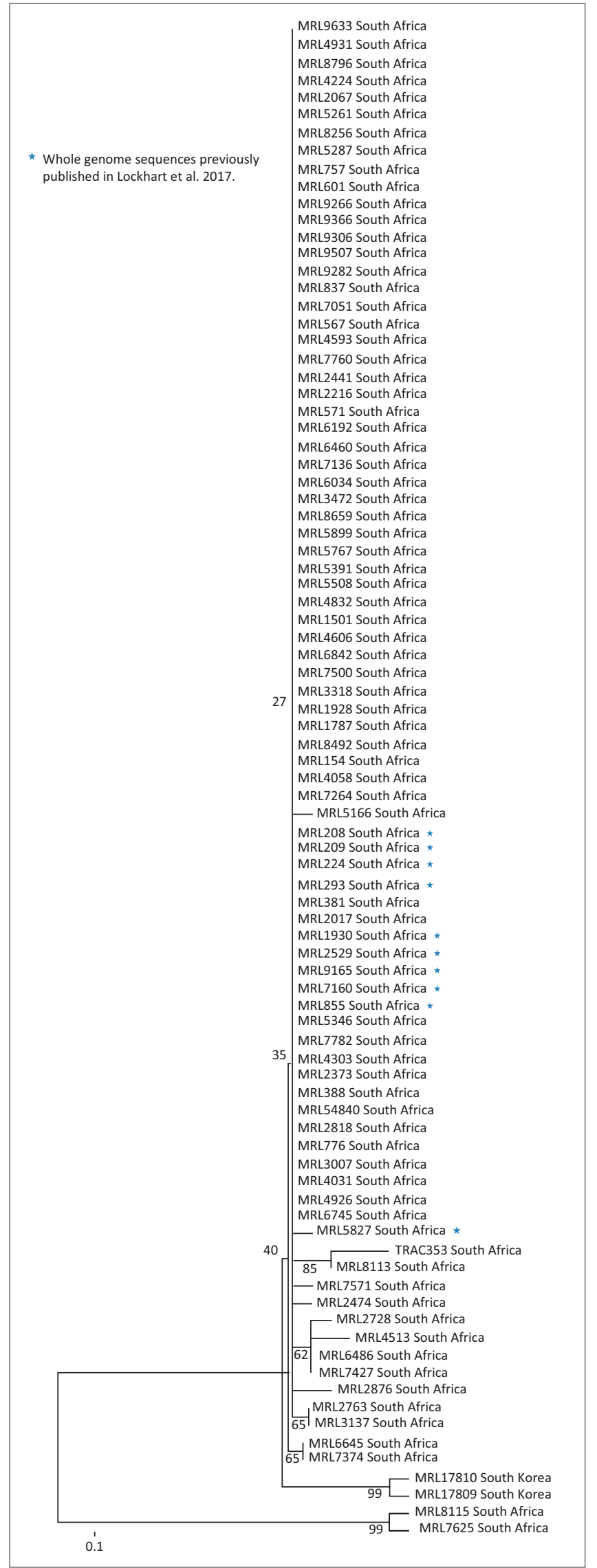

Note: Star denotes whole genome sequences previously published in Lockhart et al. (2017).

FIGURE 1: Phylogenetic tree based on multilocus sequence typing (MLST) data of South African Candida auris $(n=85)$ isolates using the neighbour-joining analysis method with 2000 bootstrap replications. Sequences of South Korean reference strains (KCTC17809 and KCTC17810) were retrieved from the GenBank.

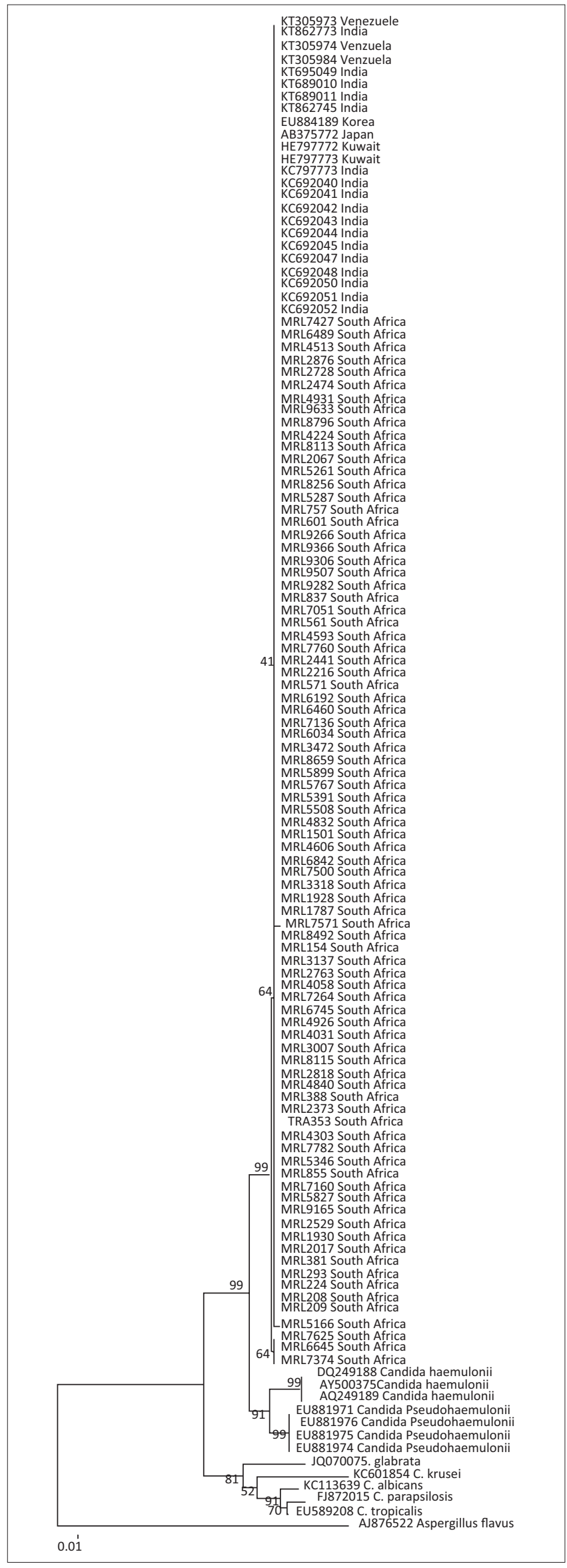

FIGURE 2: Phylogenetic tree of isolates of the Candida auris $(n=85)$ obtained using neighbour-joining phylogenetic analyses and 2000 bootstrap replications based on internal transcribed spacer sequences. 
and echinocandin. Despite being cultured from patients admitted to $>30$ hospitals, isolates were largely clonal by MLST. A more discriminatory technique, for example, WGS, probably needs to be used to explore isolate relatedness in more detail.

Azole-resistant $C$. parapsilosis is already endemic in privatesector hospitals in Gauteng Province. ${ }^{27}$ We have previously hypothesised that these strains of azole-resistant $C$. parapsilosis initially emerged as a consequence of indiscriminate use of fluconazole for prophylaxis or treatment, and transmission of this pathogen within hospitals then occurred owing to suboptimal adherence to infection prevention and control practices. ${ }^{27,28}$ This is the same setting in which C. auris, another azole-resistant pathogen emerged several years ago, ${ }^{6}$ has become endemic and has recently caused several large hospital outbreaks. ${ }^{26}$

Several studies have reported multidrug resistance in C. auris. ${ }^{2,3,4,5,6,7}$ Our study confirms that majority of isolates have elevated fluconazole MICs. In a recent WGS study, fluconazole resistance among 10 South African strains was mediated by an F126T substitution in the ERG11 gene. ${ }^{10}$ The emergence of yet another fluconazole-resistant pathogen in our setting is worrisome, especially in public-sector South African hospitals where echinocandins are available only in tertiary centres. Eight per cent of the studied isolates were resistant to both fluconazole and echinocandin. Multidrug resistance is concerning because this limits treatment to amphotericin B or a combination of antifungal agents. There is no current evidence that strains with elevated echinocandin MICs are associated with clinical failure, with the exception of central nervous system and urinary tract infections (owing to poor penetration of echinocandins into these compartments). Interestingly, we were not able to document any mutations in the FKS1 or FKS2 genes, even among strains with relatively high echinocandin MICs. Phenotypic echinocandin resistance in these isolates may be mediated by other mechanisms such as enhanced chitin expression and other point mutations outside the hot spot regions of FKS1 and FKS2 genes..$^{29,30,31}$ Mutations outside the hot spot regions may have a compensatory effect on the gene leading to alteration in the protein structure that causes variation in the MIC. ${ }^{30,31}$ Echinocandin resistanceassociated point mutations have been recently identified in FKS1 HS1 (S639F/P) of C. auris strains exhibiting MIC levels $\geq 4 \mu \mathrm{g} / \mathrm{mL} \cdot{ }^{20,32,33}$ We found some evidence of elevated isavuconazole MICs despite this agent not being available in South Africa. While isavuconazole is efficacious for the treatment of invasive aspergillosis and mucormycosis, there is limited evidence of its efficacy in treating invasive candidiasis. ${ }^{34}$ Five of our tested strains had flucytosine MICs of $64 \mu \mathrm{g} / \mathrm{mL}$; in contrast, $47 \%$ of isolates were flucytosine non-wild type in an Indian study. ${ }^{9}$ This may reflect differing patterns of flucytosine use. Flucytosine is neither registered nor available in South Africa. ${ }^{35}$ Amphotericin B will continue to be recommended as the first-line treatment option for C. auris infections in publicsector hospitals where echinocandins are not accessible. ${ }^{13,36,37}$
Combined with the results of classic epidemiologic investigations, molecular data can provide evidence of horizontal transmission in healthcare settings and guide infection prevention and control efforts. Genetic relatedness among C. auris isolates has been previously reported. These studies demonstrated that the strains were clonal using pulsed-field gel electrophoresis (PFGE), MLST, AFLP and MALDI-TOF. ${ }^{11,14}$ Another study of isolates from four different countries showed that isolates clustered by geographic regions, when MLST and MALDI-TOF were used. However, South African isolates scattered among different clusters suggesting that different genotypes may be circulating in the country. ${ }^{14}$ Whole genome sequencing of 10 strains of $C$. auris strains from South Africa (strains also included in this study) demonstrated that these strains were highly clonal with a few SNPs $\left(<70\right.$ SNPs) ${ }^{10}$ Using MLST, we have demonstrated that $C$. auris strains are highly related despite being isolated from patients admitted to a large number of hospitals; however, this assay was unable to discriminate strains from different hospitals. This suggests either that clonal strains are circulating or that the method is insufficiently discriminatory. Therefore, a more robust and discriminatory method such as WGS may be needed to demonstrate intra-species variability and nosocomial transmission. Microsatellite genotyping has been used extensively in the detection of C. parapsilosis outbreaks in neonatal intensive care units (ICUs) and was shown to be highly discriminatory in uncovering undetected outbreaks. ${ }^{38,39,40,41}$ However, it is difficult to create a microsatellite system for largely clonal pathogen, and this is also a labour-intensive process. Thus, WGS may offer a convenient, although relatively more costly, approach. ${ }^{10}$

This passive surveillance system was limited in several respects. Cases were diagnosed based on clinicians submitting appropriate specimens for fungal culture. Diagnostic laboratories only referred a small proportion of suspected or confirmed C. auris isolates to NICD, and referral of suspected antifungal-resistant strains may have biased the reported antifungal susceptibility profile. ${ }^{26}$ NICD's national active surveillance system for candidaemia (GERMS-SA) will provide a more representative picture of the scale of $C$. auris infection in South Africa. ${ }^{42}$ We envisage undertaking further molecular genotyping using WGS as this is currently the widely used technique to type C. auris isolates.

\section{Conclusion}

Azole-resistant C. auris strains circulating in Gauteng hospitals were related by MLST but the possibility of nosocomial transmission should be explored using a more discriminatory technique, for example, WGS.

\section{Acknowledgements}

The authors acknowledge the technical assistance provided by the staff members of the National Institute for Communicable Diseases (Centre for Healthcare-Associated Infections, Antimicrobial Resistance and Mycoses). 


\section{Competing interests}

For unrelated activities over the last 36 months, Nelesh P. Govender has received a speaker honorarium from Astellas and a travel grant from MSD (Pty)Ltd. For the remaining authors, none were declared.

\section{Authors' contributions}

All authors contributed equally to this article.

\section{Funding information}

This surveillance project was supported by the National Institute for Communicable Diseases.

\section{Data availability statement}

Data sharing is not applicable to this article as no new data were created or analysed in this study.

\section{Disclaimer}

The views and opinions expressed in this article are those of the authors and do not necessarily reflect the official policy or position of any affiliated agency of the authors.

\section{References}

1. Satoh K, Makimura K, Hasumi Y, Nishiyama Y, Uchida K, Yamaguchi H. Candida auris sp. nov., a novel ascomycetous yeast isolated from the external ear canal of an inpatient in a Japanese hospital. Microbiol Immunol. 2009;53(1):41-44. https://doi.org/10.1111/j.1348-0421.2008.00083.x

2. Kim MN, Shin JH, Sung $\mathrm{H}$, et al. Candida haemulonii and closely related species at 5 university hospitals in Korea: Identification, antifungal susceptibility, and clinical features. Clin Infect Dis. 2009;48(6):57-61. https://doi.org/10.1086/597108

3. Shin JH, Kim M, Jang SJ, et al. Detection of amphotericin B resistance in Candida haemulonii and closely related species by use of the Etest, Vitek-2 Yeast susceptibility system, and CLSI and EUCAST broth microdilution methods. J Clin Microbiol. 2012;50(6):1852-1855. https://doi.org/10.1128/JCM.06440-11

4. Lee WG, Shin JH, Uh Y, et al. First three reported cases of nosocomial fungemia caused by Candida auris. J Clin Microbiol. 2011;49(9):3139-3142. https://doi. org/10.1128/JCM.00319-11

5. Chowdhary A, Sharma C, Duggal S, et al. New clonal strain of Candida auris, Delhi India. Emerg Infect Dis. 2013;19(10):1670-1673. https://doi.org/10.3201/ eid1910.130393

6. Magobo RE, Corcoran C, Seetharam S, Govender NP. Candida auris-associated candidemia, South Africa. Emerg Infect Dis. 2014;20(7):1250-1251. https://doi. org/10.3201/eid2007.131765

7. Emara M, Ahmad S, Khan Z, et al. Candida auris Candidemia in Kuwait 2014. Emerg Infect Dis. 2015;21(6):1091-1092. https://doi.org/10.3201/ eid2106.150270

8. Heath $\mathrm{CH}$, Dyer JR, Pang S, Coombs GW, Gardam DJ. Candida auris sternal osteomyelitis in a man from Kenya visiting Australia, 2015. Emerg Infect Dis. 2019;25(1):192-194. https://doi.org/10.3201/eid2501.181321

9. Chowdhary A, Anil Kumar V, Sharma C, et al. Multidrug-resistant endemic clonal strain of Candida auris in India. Euro J Clin Microbiol Infect Dis. 2014;33(6):919-926. https://doi.org/10.1007/s10096-013-2027-1

10. Lockhart SR, Etienne KA, Vallabhaneni $S$, et al. Simultaneous emergence of multidrug resistant Candida auris on three continents confirmed by whole genome sequencing and epidemiological analyses. Clin Infect Dis. 2017;64(2):134-140. https://doi.org/10.1093/cid/ciw691

11. Schelenz S, Hagen F, Rhodes JL, et al. First hospital outbreak of the globally emerging Candida auris in a European hospital. Antimicrob Resist Infect Control. 2016;5:35. https://doi.org/10.1186/s13756-016-0132-5

12. Oh BJ, Shin JH, Kim MN, et al. Biofilm formation and genotyping of Candida haemulonii, Candida pseudohaemulonii, and a proposed new species (Candida auris) isolates from Korea. Med Mycol. 2011;49(1):98-102. https://doi.org/10.31 09/13693786.2010.493563

13. Centers for Disease Control and Prevention. Clinical alert to U.S. healthcare facilities: Global emergence of invasive infections caused by the multidrugresistant yeast Candida auris 2016 [homepage on the Internet]. [cited 2017 Oct 20]. Available from: https://www.cdc.gov/fungal/diseases/candidiasis/candidaauris-alert.html
14. Prakash A, Sharma C, Singh A, et al. Evidence of genotypic diversity among Candida auris isolates by multilocus sequence typing, matrix-assisted laser desorption ionization-time of flight mass spectrometry and amplified fragment length polymorphism. Clin Microbiol Infect. 2016;22(3):277.e1-277.e9. https:// doi.org/10.1016/j.cmi.2015.10.022

15. Vallabhaneni $S$, Kallen $A$, Tsay $S$, et al. Investigation of the first seven reported cases of Candida auris, a globally emerging invasive, multidrug-resistant fungusUnited States, May 2013-August 2016. Am J Transplant. 2017;17(1):296-269. United States, May 2013-August
https://doi.org/10.1111/ajt.14121

16. Borman AM, Szekely A, Johnson EM. Isolation of the emerging pathogen Candida auris present in the UK have several geographic origins. Med Mycol. 2017;55(5):563-567. https://doi.org/10.1093/mmy/myw147

17. Mizusawa M, Miller H, Green R, et al. Can multidrug-resistant Candida auris reliably identified in clinical microbiology laboratories? J Clin Microbiol. 2017;55(2):638-640. https://doi.org/10.1128/JCM.02202-16

18. White TJ, Bruns T, Lee S, Taylor J. Amplification and direct sequencing of fungal ribosomal RNA genes for phylogenetics. In: Innis MA, Gelfand H, Sninsky JJ, White TJ, editors. PCR protocols: A guide to methods and application. London: Academic Press, 1990; p. 315-322. https://doi.org/10.1016/B978-0-12-372180-8.50042-1

19. Centers for Disease prevention and control. Recommendations for healthcare facilities and laboratories [homepage on the Internet]. [cited $2018 \mathrm{Jul}$ 02]. Available from: https://www.cdc.gov/fungal/candida-auris/recommendations.html

20. Kordalewska M, Lee A, Steven Park S, et al. Understanding echinocandin resistance in the emerging pathogen Candida auris. Antimicrob Agents Chemother. 2018;62(6):pii: e00238-18. https://doi.org/10.1128/AAC.00238-18

21. Garcia-Effron G, Katiyar SK, Park S, Edlind TD, Perlin DS. A naturally occurring proline-to-alanine amino acid change in Fks1p in Candida parapsilosis, Candida orthopsilosis, and Candida metapsilosis accounts for reduced echinocandin susceptibility. Antimicrob Agents Chemother. 2008;52(7):2305-2312. https://doi. org/10.1128/AAC.00262-08

22. Castanheira M, Woosley LN, Diekema DJ, Messer SA, Jones RN, Pfaller MA. Low prevalence of fks1 Hot Spot 1 mutations in a worldwide collection of Candida strains. Antimicrob Agents Chemother. 2010;54(6):2655-2659. https://doi. org/10.1128/AAC.01711-09

23. Sharma C, Kumar N, Meis JF, Pandey R, Chowdhary A. Draft genome sequence of a fluconazole-resistant Candida auris strain from a candidemia patient in India. Genome Announc. 2015;3(4):e00722-15. https://doi.org/10.1128/ genomeA.00722-15

24. Thompson JD, Higgins DG, Gibson TJ. Clustal W: Improving the sensitivity of progressive multiple sequence alignment weighting, position specific gap penalties, weight matrix choice. Nuclei Acids Res. 1994;22(22):4673-4680. https://doi.org/10.1093/nar/22.22.4673

25. Tamura K, Stecher G, Peterson D, Filipski A, Kumar S. MEGA6: Molecular evolutionary genetics analysis version 6.0. Mol Biol Evol. 2013;30(12):2725-2729. https://doi.org/10.1093/molbev/mst197

26. Govender NP, Magobo RE, Mpembe R, et al. Candida auris in South Africa, 20122016. Emerg Infect Dis. 2018;24(11):2036-2040. https://doi.org/10.3201/ eid2411.180368

27. Govender NP, Patel J, Magobo RE, et al. Emergence of azole-resistant Candida parapsilosis causing bloodstream infection: Results from laboratory-based sentine surveillance, South Africa. J Antimicrob Chemother. 2016;71(7):1994-2014. https:// doi.org/10.1093/jac/dkw091

28. Magobo RE, Naicker SD, Wadula J, et al. Detection of neonatal unit clusters of Candida parapsilosis fungemia by microsatellite genotyping: Results from laboratory-based sentinel surveillance, South Africa, 2009-2010. Mycoses. 2007;20(7):1250-1252. https://doi.org/10.1111/myc.12596

29. Lee KK, Maccallum DM, Jacobsen MD, et al. Elevated cell wall chitin in Candida albicans confers echinocandin resistance in vivo. Antimicrob Agents Chemother. 2012;56(1):208-217. https://doi.org/10.1128/AAC.00683-11

30. Castanheira M, Woosley LN, Messer SA, Diekema DJ, Jones RN, Pfaller MA Frequency of FKS mutations among Candida glabrata isolates from 10-year global collection of bloodstream infection isolates. Antimicrob Agents Chemother. 2014;58(1):577-580. https://doi.org/10.1128/AAC.01674-13

31. Fernández-Silva F, Lackner M, Javier Capilla J, et al. In vitro antifungal susceptibility of Candida glabrata to caspofungin and the presence of FKS Mutations correlate with treatment response in an immunocompromised murine model of invasive infection. Antimcrob Agents Chemother. 2014;58(7):3646-3649. https://doi. org/10.1128/AAC.02666-13

32. Chowdhary A, Prakash A, Sharma C, et al. A multicentre study of antifungal susceptibility patterns among 350 Candida auris isolates (2009-17) in India: Role of the ERG11 and FKS1 genes in azole and echinocandin resistance. J Antimicrob Chemother. 2018;73(4):891-899. https://doi.org/10.1093/jac/dkx480

33. Berkow EL, Lockhart SR. Activity of CD101, a long-acting echinocandin against clinical isolates of Candida auris. Diagn Microbiol Infect Dis. 2018;90(3):196-197. https://doi.org/10.1016/j.diagmicrobio.2017.10.021

34. Wilson DT, Dimondi VP, Johnson SW, Jones TM, Drew RH. Role of isavuconazole in the treatment of invasive fungal infections. Ther Clin Risk Manag. 2016:12:1197-1206. https://doi.org/10.2147/TCRM.S90335

35. Govender NP, Meintjes G, Banoo S. Access to flucytosine for HIV-infected patients with cryptococcal meningitis - An urgent need. S Afr Med J. 2014;104(9):594-595. https://doi.org/10.7196/SAMJ.8713

36. Public Health England. Guidance for the laboratory investigation, management and infection prevention and control for cases of Candida auris 2016 [homepage on the Internet]. [cited 2018 Oct 20]. Available from: http://www.gov.uk/ government/collections/candida-auris 
37. National Institute for Communicable Diseases. Interim guidance for management of Candida auris infections in South African hospitals [homepage on the Internet]. [cited 2017 Oct 20]. Available from: http://www.nicd.ac.za/index.php/interimguidence-for-management-of-candida-auris-infections-in-south-africanhospitals/

38. Lasker BA, Butler G, Lott TJ. Molecular genotyping of Candida parapsilosis Group clinical isolates by analysis of polymorphic microsatellite markers. J Clin Microbiol. 2006;44(3):750-759. https://doi.org/10.1128/JCM.44.3.750-759.2006

39. Vaz C, Sampaio P, Clemons KV, Huang YC, Stevens DA, Pais C. Microsatellite multilocus genotyping clarifies the relationship of Candida parapsilosis strains involved in a neonatal intensive care unit outbreak. Diagn Microbiol Infect Dis. 2011;71(2):159-162. https://doi.org/10.1016/j.diagmicrobio.2011.05.014
40. Reiss E, Lasker BA, Lott TJ, et al. Genotyping of Candida parapsilosis from three neonatal intensive care units (NICUs) using a panel of five multilocus microsatellite markers: Broad genetic diversity and a cluster of related strains in one Nicu. Infect

41. Romeo O, Delfino D, Cascio A, et al. Microsatellite-based genotyping of Candida parapsilosis sensu stricto isolates reveals dominance and persistence of a particular epidemiological clone among neonatal intensive care unit patients. Infect Genet Evol. 2013;13:105-108. https://doi.org/10.1016/j.meegid.2012.09.006

42. Van Schalkwyk E, Shuping L, Ismail H, Thomas J, Govender NP. Independent risk factors associated with Candida auris candidaemia in South Africa - An analysis of national surveillance data, 2016-2017. In: Oral Presentation Abstracts of the 7th Conference of the Federation of Infectious Disease Societies of Southern Africa (FIDSSA); Cape Town, South Africa; 2017 Nov 9-11; Abstract ID8382. S Afr J Infect Dis. 2017 Suppl. 